\title{
The Sacroiliac Joint Injection
}

\author{
Hesham M. Farhoud ${ }^{1}$, Ashraf M. Enite ${ }^{2}$, Abd Elkhalek AlZalabany ${ }^{1}$, \\ Tarek M. Elatar ${ }^{1 *}$ \\ Departments of ${ }^{1}$ Orthopedic Surgery and ${ }^{2}$ Radiology \\ Faculty of Medicine (for girls), Al-Azhar University, Egypt
}

*Corresponding author: Tarek M. Elatar, Mobile: 01010283986, E-mail: tareeeek16@ gmail.com

\begin{abstract}
Background: the sacroiliac joint (SIJ) is the largest axial joint in the body, with an average surface area of $17.5 \mathrm{~cm}^{2}$, it is an accepted source of low back and/or buttock pain with or without lower extremity pain. Based upon history and physical examination findings, the prevalence of sacroiliac joint pain in chronic low back pain population has been shown to range from $22.5 \%$ to $62.8 \%$. Aim of this work: to evaluate the therapeutic benefit of intra articular corticoid injections into the sacroiliac joints in a standardized fashion. Patients and Methods: This study included 20 adults with SIJ pain due to different reasons and who were scheduled to undergo SIJ injection of corticosteroids and local anesthetic. Demographic data to consider includes sex, age, weight, occupation, affected side, co morbidity and suggested pathology of the examined SIJ. Results: there is significant decrease of the inflammatory back pain in $85 \%$ of patients; on mean post $2.00 \pm 1.86$ compared to pre $7.50 \pm 1.24$ according to VAS of patients after 6 months follow up ( $p$-value $<0.001 \mathrm{HS}$ ). Its minimally invasive procedure \& good result by single injection to all patients during 6 months follow up. Conclusion: CT guided sacroiliac joint minimally invasive, short time, very accurate and good results obtained. Intra articular SIJ injection is an effective method for alleviating pain in patients suffers from SIJ pain at least in short term.
\end{abstract}

Key words: Sacroiliac Joint, intra articular injection

\section{Introduction}

Sacroiliac joint (SIJ) pathology is a common cause of low back pain (LBP), accounting for $10-27 \%$ of cases of mechanical LBP below L5 level ${ }^{(\mathbf{1}, \mathbf{2})}$. If there is no definite clinical or radiological diagnostic criteria for SIJ pain, intra articular injection of SIJ have become the choice assessment method for making the diagnosis of SIJ pain. There is good results for diagnostic SIJ injections by using local anesthetic or placebo blocks and 75 $100 \%$ pain relief as the diagnostic for sacroiliitis $^{(3)}$. SI joint pain definition is a pain localized in the region of the SI joint, stimulated by special tests of the SI joint, and improved by selective infiltration of the SI joint by a local anesthetic. Depending on the diagnostic criteria For diagnosis of SIJ pain (clinical examination, intra articular blocks, Radiological investigateion), the reported prevalence of SI pain through thepatients with axial LBP accounting for $16 \%$ and $30 \%{ }^{(2-4)}$. The SI joint is a diarthrodial synovial joint. The anterior part is a true synovial joint. The posterior part is a syndesmosis consisting of the sacroiliac Ligaments, the gluteus muscle (medius and minimus), and the piriformis Muscle. The SI joint cannot function independently because all of these muscles are shared with the hip joint. The ligamentous structures and the muscles that they support influence the stability of the SI joint. The SI joint is innervated mainly by the sacral rami dorsales ${ }^{(5)}$. The anatomical structure, innervations, presence of sinusoids around the joint, and inter-individual variations in structure make SIJ injections difficult to accomplish without any guidance (e.g., fluoroscopy, computerized tomography (CT), ultrasound). Clinically-guided SIJ injections without radiographic guidance have been reported to result in low rates of intra-articular injections, spread into sacral foramina, extension into the epidural space, and vascular uptake ${ }^{(6)}$.Sacroiliitis is an inflammatory process of the sacroiliac (SI) joints involving one or both sides. It is one of the major clinical features of spondyloarthropathies. Managementfor sacroiliitis include nonsteroidal anti-inflammatory drugs and the application of physical modalities.However, in severe painful cases, local treatment of the SI joint through intraarticular corticosteroid 
injection can provide fast and considerable clinical improvements ${ }^{(7)}$.

Aim of the Work

To evaluate the therapeutic benefit of intra articular corticoid injections into the sacroiliac joints in a standardized fashion, where the injections would give high success rate and overall results of the SIJ injections in patients with SIJ pain in 6 months follow up.

\section{Patients and Methods}

This study was carried out on 20 adults with back pain around the SIJ due to different reasons and who are scheduled to undergo SIJ injection of corticosteroids and local anesthetic.

Patients with sacroiliac joint pain were admitted to the hospital and assessed for the study and gave a detailed history includes:

1- History:

- Present History

- Past History

- Complaints

2- Clinical examination:

- General examination

- Local examination

3- Laboratory investigations:

- C-reactive protein (CRP)

- Blood sedimentationrate (BSR)

- HLA-B27

\section{Inclusion criteria:}

1. Laterally located pain over the SIJ line.

2. Positive findings on at least one of the following three provocation tests for SIJ pain:

2.1. Distraction test or anterior gapping test.

2.2. Compression test or posterior gapping test.

Sacral thrust or downward pressure test.

Cranial shear test.

Posterior shear or thigh trust test.

Pelvic torsion or Gaenslen's test.

Yeoman test.

Patrick's or 'Faber' test.

\section{Exclusion criteria:}

- Signs of lumbar radiculopathy.
- Findings suspicious of infectious arthritis on the laboratory investigation or on plain radiographs.

\section{* Medication:}

The injection included mixture of triamcinoloneacetonide $1 \mathrm{ml}(40 \mathrm{mg} / \mathrm{ml})$ and mepivacaine $4 \mathrm{cc}$.

\section{* Consent:}

Informed consent was obtained from the patient prior to the procedure.

\section{* Injection Technique:}

In all patients the procedure was done under CT guided in (CT room) or fluoroscopy guided in (operative room).

Fluoroscopy guided Injection technique done in operative room in prone position under aseptic technique with prophylactic antibiotic was given preoperative. Surgical draping was done. The dimple at the top of the buttock indicates the position of the posterior superior iliac spine. Spinal needle of $22 \mathrm{G}$ is inserted mediolaterally at an oblique lateral angle of 45 degrees $2-3 \mathrm{~cm}$ below the PSIS, and passed between the sacrum and the ilium until the post ligamentous resistance is felt.

The CT-guided SIJ injections were done by a single physician. The patients were placed in a prone position, and radiographic markers were placed medial to the Sacroiliac joint (per pre-operative CT images). Local, surface anesthetic was applied to the skin. Under the guidance of CT, a 3.5 inches $(10 \mathrm{~cm})$ 22 gauge spinal needle was inserted and advanced laterally toward the SIJ. The needle was used to inject $3 \mathrm{ml}$ of $0.5 \%$ mepivacaine and $40 \mathrm{mg}$ triamcinoloneacetonide into the SIJ. Although the latter steroid injection targeted the inflammation for longterm pain relief, the former anesthetic was intended for both diagnostic and therapeutic purposes. The immediate relief provided by the mepivacaine not only confirms the proper placement of the needle but also identifies the SIJ as the primary cause of the back pain. When reporting symptomatic relief, the needle was extract, and the skin was cleansed. The patient vitals and pain scores were monitored to ensure any adverse reactions to the injections. Patients were discharged the same day. 


\section{Assessment of clinical outcome}

- Prior to treatment, all patients were evaluated using visual analog scale (VAS) Fig (1) ranging from 0 (no pain) to10 (maximum pain).

- Pain intensity was recorded prior to the intervention and daily for the first week after treatment and through telephone interviews once a month for a 6-month followup period.
- Side effects related to the intervention and female menstrual period changes were evaluated.

- The last interview was performed 6months after treatment.

- Clinical pertinent pain reduction was defined as a reduction of pain on the VAS scale of at least four points.

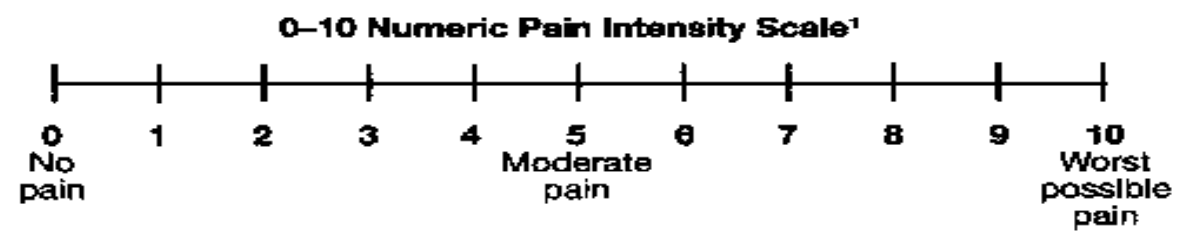

Fig. (1): visual analogue scale.Pristup 20.04.2016.

\section{STATISTICAL ANALYSIS}

Recorded data were analyzed using the statistical package for social sciences, version 20.0 (SPSS Inc., Chicago, Illinois, USA). Quantitative data were expressed as mean \pm standard deviation (SD). Qualitative data were expressed as frequency and percentage.

\section{The following tests were done:}

- When comparing between two means: Independent-samples t-test of significance was used.

- Chi-square $\left(\mathrm{x}^{2}\right)$ test of significance was used in order to compare proportions between qualitative parameters.

- The dependability interval was set to 95\% and the margin of error accepted was set to $5 \%$. So, the p-value considered significant as the following:

- P-value <0.05 was considered significant.

- P-value <0.001 was considered as highly significant.

- P-value >0.05 was considered insignificant.

\section{Results}

The primary outcome of this study was to determine the success rate of the SIJ Injection. The distribution of the studied patients regarding the CT \& Fluoroscopy Guided SIJ Injectionin studied group. It was found that the success rate in the patients was $85 \%$ and the other $15.0 \%$ of the patients Failed.

Table (1): Comparison between pre and post according to VAS

\begin{tabular}{|l|l|l|l|l|l|}
\hline VAS & Range & Mean \pm SD & Mean Diff. & t-test & p-value \\
\hline Pre & $5-\mathrm{a} 9$ & $7.50 \pm 1.24$ & 5.5 & 13.098 & $<0.001^{*}$ \\
\hline Post & $0-\mathrm{a} 6$ & $2.00 \pm 1.86$ & & & \\
\hline
\end{tabular}

Table (1) shows highly statistically significant decrease on mean post compared to pre according to VAS.

Table (2): Outcome distribution of the study group

\begin{tabular}{|l|l|l|}
\hline Outcome & Frequency & Percent \\
\hline Successful & 17 & 85 \\
\hline Failed & 3 & 15 \\
\hline Total & 20 & 100 \\
\hline
\end{tabular}

Table (2) shows that the successful (85\%) and failed (15\%) of outcome. 
The Sacroiliac Joint Injection

Table (3): Relation between outcome and sex

\begin{tabular}{|l|l|l|l|l|l|l|}
\hline \multirow{3}{*}{ Sex } & \multicolumn{2}{|l|}{ Outcome } & \multicolumn{2}{l|}{ Failed } & \multicolumn{2}{|l|}{ Chi-square test } \\
\cline { 2 - 7 } & Successful & No. & \% & x2 & p-value \\
\cline { 2 - 6 } & No. & \% & 2 & $66.7 \%$ & \multirow{2}{*}{0.065} & \multirow{2}{*}{0.798} \\
\hline Female & 10 & $58.8 \%$ & 1 & $33.3 \%$ & & \\
\hline Male & 7 & $41.2 \%$ & 3 & $100.0 \%$ & \\
\hline Total & 17 & $100.0 \%$ & &
\end{tabular}

This table shows no statistically significant relation between outcome and sex.

Table (4): Relation between outcome and occupation

\begin{tabular}{|c|c|c|c|c|c|c|}
\hline \multirow{3}{*}{ Occupation } & \multicolumn{4}{|c|}{ Outcome } & \multirow{2}{*}{\multicolumn{2}{|c|}{ Chi-square test }} \\
\hline & \multicolumn{2}{|c|}{ Successful } & \multicolumn{2}{|c|}{ Failed } & & \\
\hline & No. & $\%$ & No. & $\%$ & $\mathrm{x} 2$ & p-value \\
\hline Driver & 1 & $5.9 \%$ & 1 & $33.3 \%$ & \multirow{9}{*}{4.314} & \multirow{9}{*}{0.743} \\
\hline Houswife & 6 & $35.3 \%$ & 2 & $66.7 \%$ & & \\
\hline Nurse & 1 & $5.9 \%$ & 0 & $0.0 \%$ & & \\
\hline Security & 2 & $11.8 \%$ & 0 & $0.0 \%$ & & \\
\hline Seller & 1 & $5.9 \%$ & 0 & $0.0 \%$ & & \\
\hline Student & 1 & $5.9 \%$ & 0 & $0.0 \%$ & & \\
\hline Teacher & 2 & $11.8 \%$ & 0 & $0.0 \%$ & & \\
\hline No & 3 & $17.6 \%$ & 0 & $0.0 \%$ & & \\
\hline Total & 17 & $100.0 \%$ & 3 & $100.0 \%$ & & \\
\hline
\end{tabular}

This table shows no statistically significant relation between outcome and occupation.

Table (5): Relation between outcome and age

\begin{tabular}{|c|c|c|c|c|c|c|}
\hline \multirow{3}{*}{ Age (years) } & \multicolumn{4}{|c|}{ Outcome } & \multirow{2}{*}{\multicolumn{2}{|c|}{ Chi-square test }} \\
\hline & \multicolumn{2}{|c|}{ Successful } & \multicolumn{2}{|c|}{ Failed } & & \\
\hline & No. & $\%$ & No. & $\%$ & $\mathbf{x 2}$ & p-value \\
\hline$<40$ years & 7 & $41.2 \%$ & 0 & $0.0 \%$ & \multirow{4}{*}{1.961} & \multirow{4}{*}{0.375} \\
\hline $40-50$ years & 6 & $35.3 \%$ & 2 & $66.7 \%$ & & \\
\hline$>50$ years & 4 & $23.5 \%$ & 1 & $33.3 \%$ & & \\
\hline Total & 17 & $100.0 \%$ & 3 & $100.0 \%$ & & \\
\hline
\end{tabular}

This table shows no statistically significant relation between outcome and age (years).

Table (6): Relation between outcome and BMI

\begin{tabular}{|c|c|c|c|c|c|c|}
\hline \multirow{3}{*}{ BMI $\left[w t /(h t)^{\wedge 2}\right]$} & \multicolumn{4}{|c|}{ Outcome } & \multirow{2}{*}{\multicolumn{2}{|c|}{ Chi-square test }} \\
\hline & \multicolumn{2}{|c|}{ Successful } & \multicolumn{2}{|c|}{ Failed } & & \\
\hline & No. & $\%$ & No. & $\%$ & $\mathbf{x 2}$ & p-value \\
\hline Normal weight & 12 & $70.6 \%$ & 0 & $0.0 \%$ & & \\
\hline Over weight & 5 & $29.4 \%$ & 3 & $100.0 \%$ & 5.294 & $0.021 *$ \\
\hline Total & 17 & $100.0 \%$ & 3 & $100.0 \%$ & & \\
\hline
\end{tabular}

This table shows statistically significant relation between outcome and BMI.

Table (7): Relation between outcome and duration of disease (years)

\begin{tabular}{|c|c|c|c|c|c|c|}
\hline \multirow{3}{*}{$\begin{array}{l}\text { Duration of Disease } \\
\text { (years) }\end{array}$} & \multicolumn{4}{|c|}{ Outcome } & \multirow{2}{*}{\multicolumn{2}{|c|}{ Chi-square test }} \\
\hline & \multicolumn{2}{|c|}{ Successful } & \multicolumn{2}{|c|}{ Failed } & & \\
\hline & No. & $\%$ & No. & $\%$ & $\mathbf{x} 2$ & p-value \\
\hline$<3$ years & 9 & $52.9 \%$ & 1 & $33.3 \%$ & \multirow{4}{*}{2.484} & \multirow{4}{*}{0.289} \\
\hline $3-<5$ years & 4 & $23.5 \%$ & 2 & $66.7 \%$ & & \\
\hline$\geq 5$ years & 4 & $23.5 \%$ & 0 & $0.0 \%$ & & \\
\hline Total & 17 & $100.0 \%$ & 3 & $100.0 \%$ & & \\
\hline
\end{tabular}

This table shows no statistically significant relation between outcome and duration of disease (years). 
Table (8): Relation between outcome and side

\begin{tabular}{|l|c|c|c|c|c|c|}
\hline \multirow{2}{*}{ Side } & \multicolumn{4}{|c|}{ Outcome } & \multirow{2}{*}{ Chi-square test } \\
\cline { 2 - 5 } & No. & Successful & Failed & \multirow{2}{*}{ p-value } \\
\hline Bilateral & 3 & $17.6 \%$ & 0 & $0.0 \%$ & & \\
\hline Right & 5 & $29.4 \%$ & 1 & $66.7 \%$ & \multirow{2}{*}{0.630} & \multirow{2}{*}{0.730} \\
\hline Left & 9 & $52.9 \%$ & 2 & $33.3 \%$ & & \\
\hline Total & 17 & $100.0 \%$ & 3 & $100.0 \%$ & & \\
\hline
\end{tabular}

This table shows no statistically significant relation between outcome and side.

\section{Discussion}

This study prospectively investigated the therapeutic benefit of intra articular corticoid injections into the sacroiliac joints in a standardized fashion. This study was carried out on 20 adults 12 Female $\& 8$ males with back pain around the SIJ due to different reasons and who were scheduled to undergo SIJ injection of corticosteroids and local anesthetic.

A substantial reduction of inflammatory back pain of at least 4 VAS was reported by $70 \%$ (significant decrease on mean post $2.00 \pm 1.86$ compared to pre $7.50 \pm 1.24$ according to VAS) of patients after 6 months.

Sacroiliitis can have a massive immobilizing effect on patients with $\mathrm{SpA}$ and leads to a significant loss in quality of life ${ }^{(8)}$. Biologic agents and NSAID are used for systemic therapy but often aren't enough to manage clinical effects such as pain and decreased joint mobility. Furthermore, the side effects of these medications may preclude their longer use in some patients ${ }^{(9)}$. Therefore, local therapy of inflammation has evolved into an important component of disease management (10).

Due to the complex anatomy of the sacroiliac joint, local injection therapies have Avery low success rate of $12-20 \%$, if performed without image guidance (11, 12). Computed tomography in combination with CT fluoroscopy provides excellent three dimensional anatomic visualizations and guidance in realtime, which, up to this date, hasn't been matched by other modalities.

For a long time, musculoskeletal medicine gave little or no recognition to the fact that the SIJ might be the possible source of nonspecific low back pain (LBP). The only way to provide an objective answer to this question was to carry out diagnostic blockade of the symptomatic SIJ. The first study, published in
1995, was that of Schwarzeret al. ${ }^{(13)}$ who performed diagnostic sacroiliac blocks (SIJB) on 43 unselected patients with LBP, $30 \%$ of whom afterward expressed a relief of their pain $^{(13)}$.

The second was that of Maigne $\boldsymbol{e t}$ al. (15) who selected 54 patients with LBP in the form of pain in one buttock only and carried out an initial block with lidocaine. Then, if this was positive, a confirming block of bupivacaine was carried out 7 days later to limit the false positives relating to a placebo effect. Eighteen percent responded to the two successive blocks (and 35\% to the first) with more than 75\% pain relief as measured on a visual analog scale (VAS), confirming the place of the SIJ as being one of the possible sources of nonspecific lower back pain, even if the exact prevalence of this syndrome is still under debate. To date, anesthetic block remains the standard treatment for a diagnosis of pain originating in the SIJ.

The SIJ injection can be done blindly, however because the joint is narrow and access is difficult (16), this type of injection has been accepted as unreliable. Rosenberg et al. ${ }^{(17)}$ showed that only $22 \%$ of SIJ injections without image guidance were in the right place intraarticularly. Another study by Hansen (18) showed similar results in that the intraarticular injection without fluoroscopy was successful in only 5 out of 60 patients As a result, imaging guided diagnostic or therapeutic sacroiliac joint injections are gaining popularity to determine the precise structures.

\section{Efficacy of intraarticular steroid injections}

In a retrospective chart review, Slipmanet al. $^{\left({ }^{(19)}\right.}$ assessed improvement after intraarticular SIJ injection of steroid and physical therapy to treat patients experiencing symptoms of SIJ syndrome diagnosed by a single diagnostic injection with a minimum of 
an $80 \%$ decrease in the pre and post sacroiliac joint block visual analog scale (VAS) scores. Patients' symptoms duration before diagnostic injection ranged from a minimum of 1.5 months to a maximum of 84 months (average 20.6 months). Patients received an average of 2.1 injections (1-4 injections). At a mean followup of 94.4 weeks (10-160 weeks), VAS scores were reduced by $43 \%$ in 31 patients (12 men and 19 women). At follow-up, there was a statistically and clinically significant improvement in the VAS pain scores. However, there is a key limitation to this study. The study is retrospective with no control group for comparison. Without a control group, the effects of natural history on the observed outcomes are not clear.

In a prospective double blind randomized control trial, Maugerset $\boldsymbol{a l}^{\left({ }^{(20)}\right.}$ randomized 13 patients with spondyloarthropathy and low back pain experiencing symptoms of SIJ pain syndrome based on history and physical examination to a fluoroscopically guided SIJ corticosteroid versus saline injection. No diagnostic injections were performed. At 1 month, there was a clinically significant improvement in the corticosteroid group (5/6 vs. 0/7) with very good or good improvement. Although this study further supports Slipman's findings, these findings may not apply to patients experiencing symptoms of sacroiliac joint syndrome without spondyloarthropathy ${ }^{(21)}$.

In a prospective study, Lilianget al. ${ }^{(22)}$ used intraarticular SIJ injection of steroid in 39 patients experiencing symptoms of sacroiliac joint syndrome without spondyloarthropathy diagnosed by a dual diagnostic injection paradigm defined at least a $75 \%$ pain reduction for 1 to 8 hours on both blocks. The solution consisted of $1 \mathrm{~mL} 0.5 \%$ bupivacaine or $2 \%$ lidocaine, mixed with $1 \mathrm{~mL}$ (40mg) triamcinolone acetonide. All 39 patients included in the study had two separate SIJ injections prior to assessment. Of the 39 patients who underwent dual SIJ blocks with triamcinolone acetonide, $26 \quad(66.7 \%)$ experienced more than $50 \%$ pain reduction for more than 6 weeks, which presented a successful response in these patients. The overall mean duration of pain reduction in the 26 responders to the second SIJ block was 36.8 \pm 9.9 weeks (range, 12-60 weeks). Of these 26 responders, 8 showed recurrence of pain and received the third block with triamcinolone acetonide. Thirteen patients responded to sacroiliac joint blocks for a short time, with a mean duration of pain reduction $4.4 \pm 1.8$ weeks (range, 1-6 weeks). Of the no responders, seven out of thirteen had a history of a lumbosacral fusion and/or bilateral symptoms ${ }^{(23)}$.

Sacroiliitis is the most common manifestation of axial spondyloarthritis. About $95 \%$ of patients with ankylosing spondylitis (AS) will develop sacroiliitis, and it is believed that the sacroiliac joint is one of the locations where the disease starts ${ }^{(23)}$.

A small randomized, controlled, and double blind study of 10 patients with symptomatic active sacroiliitis (8 patients with AS and 2 patients with SAPHO syndrome) showed a decrease in pain scores in the SIJ over 6 months for the glucocorticoid group in comparison to a placebo group ${ }^{(24)}$.

An older study using CT-guided injection in $30 \mathrm{SpA}$ patients (ASandSpA) also showed an improvement in pain over 6 months (25). An experienced interventionalist can perform the procedure in $10 \mathrm{~min}^{(26)}$ and is recommended as a guidance modality of choice (27). Recently, repeated direct injections of etanercept under CT guidance have been described in a small group of patients (28), demonstrating a significant reduction of inflammatory cell count and levels of tumor necrosis factor $\alpha$ in the treated sacroiliac joints and a significant pain scale reduction for up to 2 months.

Long term studies for this treatment haven't been published so far ${ }^{(28)}$.

A current limitation is the high cost of etanercept local corticosteroids such as triamcinolone is 100 times less expensive than etanercept. Conventional CT and fluoroscopy are well confirmed methods to guide the interventional treatment of sacroiliitis. Their radiation exposure is a disadvantage to both the mostly younger patients and the interventional radiologist ${ }^{(29)}$. The bulk of exposure for the patient results from the initial unenhanced spiral CTscan (about $0.5 \mathrm{mSv}$ ), if needed.

Modern CT scanners and new exposure reduction tools such as automated dose modulation and iterative reconstruction ${ }^{(30)}$ can help to reduce these doses. The additional radiation exposure during the procedure 
depends on the interventional radiologist's experience and can be reduced up to $94 \%$ when single slice fluoroscopy is used in stead of continuous fluoroscopy and standard low dose protocols ${ }^{(28,31)}$.

These factors can reduce radiation exposure too well under $1 \mathrm{mSv}$, which is less than half of the natural yearly radiation exposure of $2.1 \mathrm{mSv}^{(32)}$. Initial results with the use of MRI guided percutaneous treatment of sacroiliitis have been reported. MRI is ansubstitutional cross sectional imaging tool with advantage of providing excellent soft tissue contrast without radiation exposition. MRI is limited by the fact that it cannot be used in claustrophobia or obesity and in patients with implanted metal devices (e.g., pacemaker) ${ }^{(33)}$.

Dedicated MRI systems have been designed to improve access to the patient and shorten procedure times. However, MRI guidance in the treatment of musculoskeletal diseaseis still about twice as expensive as CT guidance ${ }^{(34)}$.

Real time pulse sequences, needed to shorten treatment times, are being evaluated ${ }^{(35)}$.Since MRI doesn't involve radiation exposure for patients and personnel, MRI guided sacroiliac injection may be a promising alternative to the CT guided procedure.

Ultrasound guided sacroiliac joint injection is another imaging modality that has recently been used to guide the needle into the SIJ space. Ultrasound is easy to handle, widely available and inexpensive.

Initial studies investigating ultrasound have reported a lack of direct intra articular visualization due to surface artifacts (36). Because of insufficient visualization of the intra articular portion of the joint, an indirect method with sonographic landmarks has been proposed, resulting in a technical success rate as low as $40 \%$.

Pekkafahli et al. ${ }^{(37)}$ increase the rate of correct needle positioning from $60 \%$ to up to $93.5 \%$. First experiences of a simultaneous use of CT or MRI in combination with sonography in a fusion technique for needle placement were described ${ }^{(37)}$, while other groups used MRI or CT to check the needle position after an ultrasound guided placement ${ }^{(38)}$.
Hartung et al. ${ }^{(38)}$ found no significant differences in clinical outcome parameters between intra and peri articular steroid injections in a small study of 14patients.In another small group of 10 patients, significant pain reduction with periarticular needle placement persisting for two months compared to aplacebo group was demonstrated,which at first sight disagrees with our findings.

\section{Conclusion}

\section{It can be concluded that:}

CT guided Sacroiliac joint minimally invasive, short time, very accurate \& good result good results obtained. Intra articular SIJ injection is an effective method for alleviating pain in patients suffers from SIJ pain at least in short term.

\section{References:}

1. Rupert MP, Lee M, Manchikanti L et al. (2009): Evaluation of sacroiliacjoint interventions: A systematic ap-praisal of the literature. Pain Physician, 12:399-418.

2. Simopoulos TT, Manchikanti L, Singh V et al. (2012): A systematic evaluation of preva-lence and diagnostic accuracy of sacro-iliac joint interventions. Pain Physician, 15:E305-E344.

3. Manchikanti L, Abdi S, Atluri S et al. (2013): An up-date of comprehensive evidence-basedguidelines for interventional techniques in chronic spinal pain. Part II: Guidance and recommendations. Pain Physician, 16:S49-S283.

4. Bernard TN, Kirkaldy-Willis WH (1987): Recognizingspecific characteristics of nonspecific low back pain. Clin. Orthop. Relat. Res., 266-280.

5. Schwarzer AC, Aprill CN andBogduk N (1995): The sacroiliacjointin chronic low back pain. Spine, 20:31-37.

6. Maigne JY, Aivaliklis $A$ and Pfefer $F$ (1996): Results of sacro-iliac joint double block and value of sacroiliac pain provoca-tion tests in 54 patients with low back pain. Spine, 21:1889-1892.

7. Fortin JD, Kissling RO, O'Connor BL et al. (1999): Sacroiliac joint innervation and pain. Am. J. Orthop., 28:687-690. 
8. Underwood MR, Dawes $P$ (1995): Inflammatory back pain in primarycare. Br. J. Rheumatol., 34(11):1074-7

9. Zochling J, van der Heijde D, BurgosVargas Ret al. (2006): ASAS/EULAR recommendationsfor the management of ankylosing spondylitis. Ann. Rheum. Dis., 65(4):442-52

10. Rosenberg JM, Quint TJ and de Rosayro AM (2000):Computerizedtomographic localization of clinically-guided sacroiliac joint injections.Clin J Pain ,16(1):18-21.

11. Hansen HC (2003): Is fluoroscopy necessary for sacroiliac jointinjections? Pain Physician, 6(2):155-8

12. Maugars Y, Mathis C, Berthelot JM et al. (1996): Assessment of the efficacy of sacroiliac corticosteroid injectionsinspondylarthropathies: a doubleblind study. Br. J.Rheumatol., 35(8):76770.

13. Pereira PL, Gunaydin I, Trubenbach $\mathbf{J}$ et al. (2000): Interventional MR imaging for injection of sacroiliac joints in patients with sacroiliitis. AJR. Am. J.Roentgenol., 175:265- 6.

14. Rosenberg JM, Quint TJ and de Rosayro AM (2000): Computerized tomographic localization of clinicallyguided sacroiliac joint injections. Clin. J. Pain, 16:18-21.

15. Hansen HC (2003): Is fluoroscopy necessary for sacroiliac joint injections? Pain Physician, 6:155-158.

16. Kaplan PA, Dussault RG (1997): ImageGuided Selective Nerve Blocks in the Spine. SeminMusculoskeletRadiol., 1:231-240.

17. Schwarzer AC, Aprill $\mathrm{CN}$ andBogduk N (1995): The sacroiliac joint in chronic low back pain. Spine, 20:31-7.

18. Maigne JY, Aivaliklis A andPfefer $F$ (1996): Results of sacroiliac joint double block and value of sacroiliac pain provocation tests in 54 patients with low back pain. Spine, 21:1889-92.
19. Slipman CW, Lipetz JS, Plastaras CT et al.(2001):Fluoroscopically guided therapeutic sacroiliac joint injections for sacroiliac joint syndrome. Am. J. Phys. Med.Rehabil., 80:425-32.

20. Dussault RG, Kaplan PA and Anderson MW (2000): Fluoroscopy-guided sacroiliac joint injections. Radiology, 214:273-7.

21. Maugars $Y$, Mathis $C$, Vilon $P$ et al. (1992): Corticosteroid injection of the sacroiliac joint in the seronegativespondylarthropathy. Arthritis.Rheum., 35:564-8.

22. Plastaras CT, Joshi AB, Garvan C et al. (2012): Adverse events associated with fluoroscopically guided sacroiliac joint injections. PMR., 4:473-8.

23. Liliang PC, Lu K, Weng HC et al. (2009): The therapeutic efficacy of sacroiliac joint blocks with triamcinolone acetonide in the treatment of sacroiliac joint dysfunction without spondyloarthropathy. Spine, 34:896-900.

24. Braun J, BollowM, Seyrekbasan F et al.(1996): Computed tomography guided corticosteroid injectionof the sacroiliac joint in patients with spondyloarthropathywithsacroiliitis:

clinical outcome and followup by dynamic magneticresonance imaging. J.Rheumatol., 23(4):659-64.

25. Fischer T, Biedermann T, Hermann KG et al. (2003):Sacroiliit i s in children withspondyloarthropathy: therapeutic effect of CT-guided intraarticularcorticosteroid injection. Rofo.Fortschr.Geb.Rontgenstr.Neuen.Bil dgeb.Verfahr., 175(6):814-21.

26. D'Orazio F, Gregori LM and Gallucci M (2015): Spine epidural andsacroiliac joints injectionswhen and how to perform. Eur. J. Radiol., 84(5):777-82.

27. Cui Y, Xiao Z, Shuxia $\mathrm{W}$ et al.(2010):Computed tomography guided intra-articular injection ofetanercept in the sacroiliac joint is an effective mode of treatmentofankylosing spondylitis. Scand. J.Rheumatol., 39(3):229-32. 
28. Stoeckelhuber BM, Leibecke T, Schulz E et al. (2005): Radiation doseto the radiologist's hand during continuous CT fluoroscopy-guidedinterventions.

CardiovascInterventRadiol., $\quad 28(5): 589$ 94.

29. Karpitschka M, Augart D, Becker HC et al. (2013): Dose reduction in oncological staging multidetector $\mathrm{CT}$ : effect ofiterative reconstruction. $\mathrm{Br}$. J.Radiol., 86(1021):201-224.

30. Kloeckner R, dos Santos DP, Schneider $\mathrm{J}$ et al. (2013): Radiation exposure in CTguided interventions. Eur. J. Radiol., 82(12):2253-7.

31. Artner J, Cakir B, Reichel $\mathrm{H}$ et al. (2012): Radiation dose reductionin CTguided sacroiliac joint injections to levels of pulsed fluoroscopy:A comparative study with technical considerations. Journalof Pain Research,5:265-9.
32. Fritz J, Konig CW, Gunaydin I et al. (2005): Magnetic resonance imagingguided corticosteroid-infiltration of the sacroiliac joints: pain therapy of sacroiliitis in patientswithankylosing spondylitis. Rofo., 177(4):555-63.

33. MaurerMH, SchreiterN, deBucourt $M$ et al.(2013): Cost comparison of nerve root infiltration of the lumbarspine under MRI and CT guidance. Eur.Radiol., 23(6):1487-94.

34. Fischbach F, Eggemann H, Bunke J et al. (2012): MR-guided freehand biopsy of breast lesions in a1.0-T open MR imager with a near-real-time interactive platform:preliminary experience. Radiology, 265(2):359-70.

35. Pekkafahli MZ, Kiralp MZ, Basekim CC et al. (2003): Sacroiliac joint injections performed with sonographicguidance. J. Ultrasound Med. Off. J. Am. Inst. Ultrasound Med., 22(6):553-9.

36. Klauser AS, De Zordo T, Feuchtner GM et al. (2010): Fusion of real-time US with CT imagesto guide sacroiliac joint injection in vitro and in vivo.Radiology, 256(2):547-53.

37. Zacchino M, Almolla J, Canepari E et al. (2013): Use of ultrasound-magnetic resonance image fusion to guide sacroiliacjoint injections: a preliminary assessment. J. Ultrasound, 16(3):111-8.

38. Hartung W, Ross CJ, Straub R et al. (2010):Ultrasound-guided sacroiliac joint injection in patientswith established sacroiliitis: precise IA injection verified byMRI scanning does not predict clinical outcome. Rheumatology, 49(8):1479-82. 